\title{
CaMKII inhibitors: from research tools to therapeutic agents
}

\section{Patricia Pellicena and Howard Schulman*}

Allosteros Therapeutics, Inc., Sunnyvale, CA, USA

\section{Edited by:}

Eleonora Grandi, University of California, Davis, USA

\section{Reviewed by:}

Andrew G. Edwards, University of California, San Diego, USA

Nicole Ashpole, Oklahoma University

Health Sciences Center, USA

\section{${ }^{*}$ Correspondence:}

Howard Schulman, Allosteros

Therapeutics, Inc., 1230 Bordeaux

Drive, Sunnyvale, CA 94089-1202,

USA

e-mail: howard.schulman@gmail.com

\begin{abstract}
The cardiac field has benefited from the availability of several CaMKII inhibitors serving as research tools to test putative CaMKII pathways associated with cardiovascular physiology and pathophysiology. Successful demonstrations of its critical pathophysiological roles have elevated CaMKII as a key target in heart failure, arrhythmia, and other forms of heart disease. This has caught the attention of the pharmaceutical industry, which is now racing to develop CaMKII inhibitors as safe and effective therapeutic agents. While the first generation of CaMKII inhibitor development is focused on blocking its activity based on ATP binding to its catalytic site, future inhibitors can also target sites affecting its regulation by $\mathrm{Ca}^{2+} / \mathrm{CaM}$ or translocation to some of its protein substrates. The recent availability of crystal structures of the kinase in the autoinhibited and activated state, and of the dodecameric holoenzyme, provides insights into the mechanism of action of existing inhibitors. It is also accelerating the design and development of better pharmacological inhibitors. This review examines the structure of the kinase and suggests possible sites for its inhibition. It also analyzes the uses and limitations of current research tools. Development of new inhibitors will enable preclinical proof of concept tests and clinical development of successful lead compounds, as well as improved research tools to more accurately examine and extend knowledge of the role of CaMKII in cardiac health and disease.
\end{abstract}

Keywords: CaMKII, kinase inhibitors, cardiovascular disease, CaMKII inhibitors, AC3-I, KN-93, CaMKIINtide, KN-62

\section{INTRODUCTION}

The search for a multifunctional $\mathrm{Ca}^{2+}$-stimulated protein kinase serving to coordinate the actions of $\mathrm{Ca}^{2+}$-linked signals, in analogy to the cAMP-dependent protein kinase (PKA) already known to coordinate the actions of cAMP, led to the discovery and characterization of multifunctional $\mathrm{Ca}^{2+} /$ calmodulin (CaM)-dependent protein kinase II (CaMKII; reviewed in Hudmon and Schulman, 2002; Swulius and Waxham, 2008). Delineation of its functions and relevant substrates was initially complicated by the fact that its activator, $\mathrm{Ca}^{2+} / \mathrm{CaM}$, regulates many other enzymes. It has therefore been pharmacological inhibitors and genetic ablation or suppression of CaMKII activity that have served to define its functions. This review aims to provide the context for understanding protein kinase inhibition and specifically to describe the types of inhibitors used, their advantages, and their disadvantages. There is now the potential for better inhibitors as therapeutic agents and research tools stemming from industry interest in pursuing CaMKII-based therapeutics, due in no small measure to the cardiovascular scientists in this issue who have identified its critical role in cardiac disease.

\section{CaMKII STRUCTURE}

Among $\mathrm{Ca}^{2+} / \mathrm{CaM}$-dependent kinases CaMKII can be best claimed as the multifunctional CaM kinase because it has broad substrate specificity and is ubiquitous, with the $\gamma$ and $\delta$ isoforms present in heart, brain, and other tissues and $\alpha$ and $\beta$ present at very high levels in brain. Each of these four genes give rise to multiple isoforms, primarily by alternatively spliced sequences (Hudmon and Schulman, 2002; Tombes et al., 2003). The most distinctive feature of CaMKII among protein kinases is that it self-assembles into supramolecular structures of twelve subunits. Each subunit contains an $\mathrm{N}$-terminal catalytic domain followed by a regulatory segment of approximately 40 residues that serves an autoinhibitory function by blocking access to the catalytic site. This domain organization is typical of CaM-regulated protein kinases. The regulatory segment (or autoinhibitory domain) contains most of the elements that are critical for regulation of activity; the posttranslational modification (PTM) segment for regulation by autophosphorylation (Thr287), O-GlcNAC modification (Ser280), and oxidation (Met281/Met282), and the CaM-recognition sequence (Figure 1). We will use the amino acid numbering based on the sequence of CaMKII $\delta$, which are one higher than for the $\alpha$ isoform. Unique to CaMKII is the C-terminal hub or association domain, which is responsible for subunit oligomerization into dodecameric holoenzymes. A flexible linker of variable length connects the regulatory segment to the association domain and it is where most variability resides.

The high resolution crystal structures of the autoinhibited kinase domain and regulatory segment of $C$. elegans CaMKII (Rosenberg et al., 2005) and of all four human isoforms (Rellos et al., 2010) have been elucidated. The structures show a canonical kinase fold with an $\mathrm{N}$-terminal lobe (N-lobe) connected by a "hinge" segment to a C-terminal lobe (C-lobe), where the peptide or protein substrate binding site resides. The ATP-binding site is located at the interface between the two lobes in close proximity to the peptide substrate binding site. In these autoinhibited structures the regulatory segment forms an $\alpha$-helix of various lengths and folds back onto the kinase domain blocking access to the catalytic site (Figure 1). The critical autophosphorylation site, Thr287, 


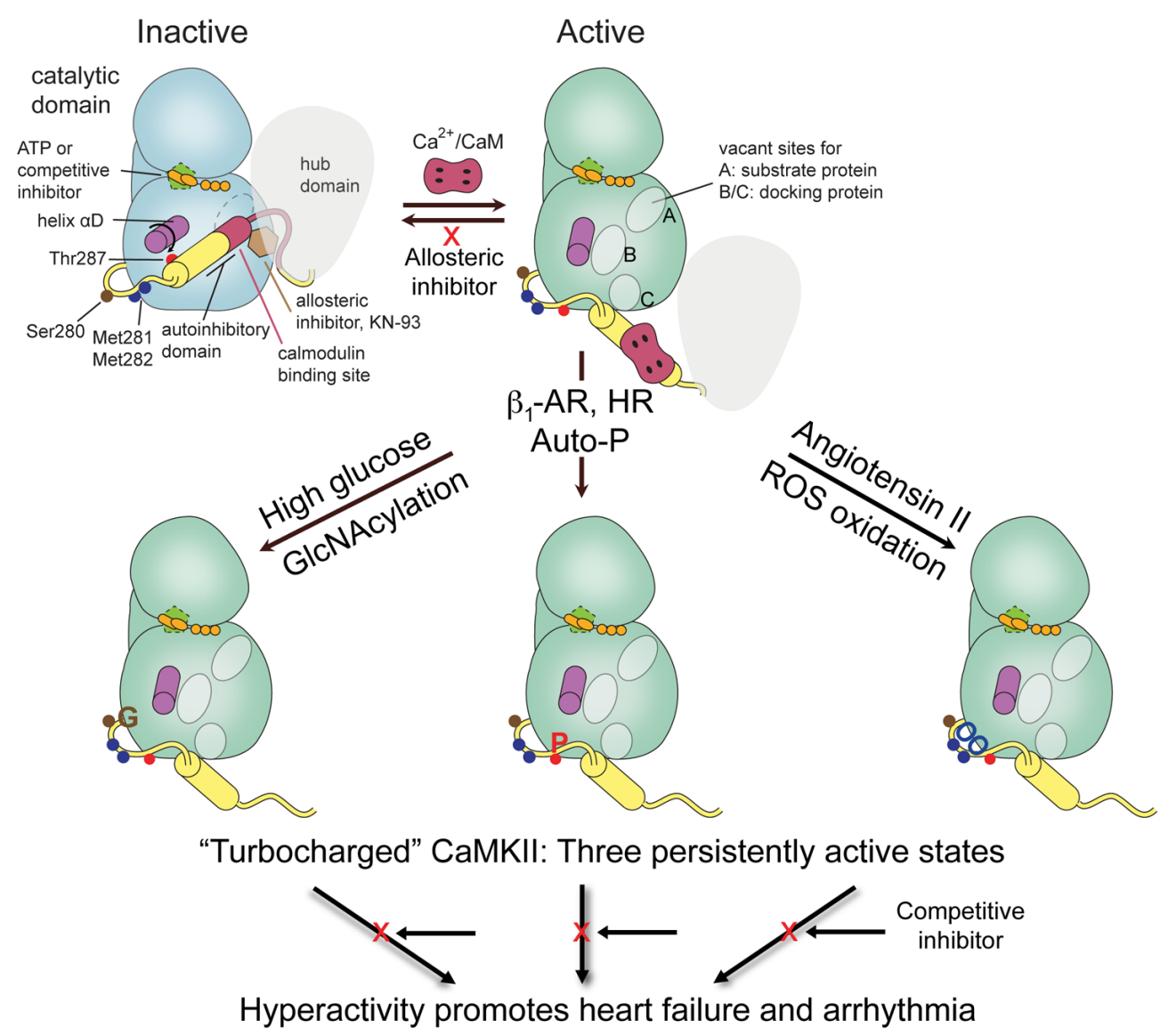

FIGURE 1 | CaMKII domain organization and schematic of activation

states. One subunit of a holoenzyme composed of hub and bi-lobed catalytic domain is shown in the inactive conformation. The autoinhibitory domain or regulatory segment contains the PTM segment, important for regulation by phosphorylation, oxidation, and GlcNAcylation, followed by the CaM binding domain. Binding of $\mathrm{Ca}^{2}+/ \mathrm{CaM}$ displaces the autoinhibitory domain leading to rearrangement of the lower or $\mathrm{C}$-lobe of the kinase allowing substrate access to the catalytic cleft and the phosphoacceptor site $A$, and formation of docking sites $\mathrm{B} / \mathrm{C}$ that can also be used for substrate specificity. Regulatory modifications at PTM segment by either $\mathrm{Ca}^{2}+/ \mathrm{CaM}$-stimulated autophosphorylation, e.g., by $\beta$-adrenergic stimulation or rapid heart rate (HR), oxidation by ROS, e.g., by Angiotensin II signaling, or GIcNAcylation by hyperglycemia disable the autoinhibitory domain to generate a persistently active or "turbocharged" CaMKII leading to cardiac pathophysiology. is buried at the base of the regulatory segment and inaccessible for phosphorylation. $\mathrm{Ca}^{2+} / \mathrm{CaM}$ binding to the regulatory segment has therefore the dual purpose of first facilitating access to the active site of the kinase by displacing the regulatory segment, and second, to make Thr287 available for phosphorylation in trans by a neighboring activated kinase subunit (Hanson et al., 1994). Phosphorylation of Thr287 likely impairs the rebinding of the autoinhibitory domain (Colbran et al., 1989) rendering the kinase "autonomous" of $\mathrm{Ca}^{2+} / \mathrm{CaM}$ and constitutively active until dephosphorylated (reviewed in Hudmon and Schulman, 2002).

The activated state seen in a crystal structure of the kinase domain with the regulatory segment displaced from the kinase domain and bound to $\mathrm{Ca}^{2+} / \mathrm{CaM}$ sheds light on the process of activation by CaM (Rellos et al., 2010). The most notable structural rearrangement is a major reorganization of a helical segment in the C-lobe of the kinase, helix $\alpha \mathrm{D}$ (Figure 1), impeding the rebinding of the CaM-displaced regulatory segment. The positional shift in helix $\alpha \mathrm{D}$ results in the reorientation of Glu97, an important ATP-coordinating residue, leading to a conformation improved for ATP-binding and catalysis (Rosenberg etal., 2005; Rellos etal., 2010). An interesting feature of this "activated" structure is that the regulatory segment adopts an extended conformation and positions Thr287 for capture and autophosphorylation by the active site of a neighboring kinase, as similarly seen in some of the C. elegans structures (Chao et al., 2010).

Studying activation states can give insights to additional strategies for inhibitor design (see below). The phosphoacceptor sequence in substrates is positioned at docking site A (previously termed S-site; Figure 1; Chao et al., 2010) and has been used in the design of peptide substrates and of "pseudosubstrate" peptides used as inhibitors. An important consequence of helix $\alpha \mathrm{D}$ reorientation is the creation of a hydrophobic pocket (first identified and termed docking site B by Chao et al., 2010) that is absent in the autoinhibited form of the kinase. This site anchors hydrophobic residues located five to eight residues $\mathrm{N}$-terminal to the phosphoacceptor site of some substrates for added specificity, and is used for intracellular targeting of the kinase and by 
peptide inhibitors such as CaMKIINtide (see below). Similarly, an acidic pocket at the base of the C-lobe designated docking site $\mathrm{C}$ provides additional interactions for orienting interacting proteins (Chao et al., 2010; Figure 1). Docking sites B/C correspond functionally to the region of the molecule referred to as the $\mathrm{T}$-site in previous studies of the autoinhibited state (Hudmon and Schulman, 2002 and references therein). Referring to these as docking sites $\mathrm{B}$ and $\mathrm{C}$ is now preferred because the site is not just vacated by the regulatory segment during activation but is altered in the process.

The holoenzyme is assembled as two hexameric rings symmetrically stacked one on top of the other with the kinase domains arranged peripherally around a central hub (Woodgett et al., 1983; Kolodziej et al., 2000; Morris and Torok, 2001; Chao et al., 2011). In an isoform lacking the linker domain, the kinase domains nestle between two hub domains with their active sites and regulatory segments completely inaccessible to $\mathrm{Ca}^{2+} / \mathrm{CaM}$. It is proposed that a dynamic equilibrium governed by the linker length between the kinase and the association domains regulates exposure to CaMbinding sites facilitating the process of holoenzyme activation (Chao et al., 2011).

The PTM segment that enables autonomous activity following autophosphorylation evolved to extend such regulation to reactive oxygen species (ROS) and glucose-linked signaling (Figure 1). Increased ROS leads to oxidation of Met 281/282 at the base of the regulatory segment (Erickson et al., 2008). Elevated glucose leads to covalent modification of CaMKII nearby at Ser280 by O-linked N-acetylglucosamine (GlcNAcylation; Erickson et al., 2013). Introduction of bulky groups to the region normally interacting with the surface of the C-lobe is expected to weaken the interaction between the two and, like Thr287 phosphorylation, keep the autoinhibitory domain displaced and the kinase persistently active (Figure 1). All three modifications, individually and together, can produce a "turbocharged" kinase with consequences for arrhythmia (Chelu etal., 2009; Purohit et al., 2013), heart failure (Anderson et al., 2011; Luo et al., 2013), asthma (Sanders etal., 2013), and diabetes (Erickson etal., 2013). There may also be additional PTM of CaMKII involving nitrosation of Cys (Gutierrez et al., 2013).

Taken together, the recent accumulation of structural information offers a clearer understanding of CaMKII regulation. These structures not only provide a foundation for the rational design and optimization of CaMKII-specific inhibitors but may also present the opportunity for novel inhibitor-design strategies that extend beyond ATP-binding sites.

\section{CaMKII INHIBITORS: FROM BENCH TO CLINIC KN-93/KN-62}

The most widely used inhibitor for study of cellular and in vivo functions of CaMKII has been KN-93 (Sumi etal., 1991; Figure 2A). It is one of a remarkable number of tool inhibitors developed by Hidaka and his colleagues for PKA, protein kinase $\mathrm{C}$ (PKC), CaMKII, and MLCK, many of which became commercially available and widely used. However, these were not on the path to therapeutic use and are therefore not optimized for potency, selectivity, or pharmacokinetics. KN-93 supplanted $\mathrm{KN}-62$ which shares structural elements and mechanism of action (Tokumitsu et al., 1990). Inhibition by both is competitive with $\mathrm{Ca}^{2+} / \mathrm{CaM}$ and not competitive with ATP. KN-62 binds to the holoenzyme and interferes with the ability of $\mathrm{Ca}^{2+} / \mathrm{CaM}$ to activate it, but does not directly bind to $\mathrm{CaM}$, i.e., it is not a $\mathrm{CaM}$ antagonist at effective inhibitory concentrations. It is worth noting, however, that a "predecessor" of KN-93 with a very similar structure, HMN-709, is a CaM antagonist (Yokokura et al., 1996; Figure 2A). Neither KN-62 nor KN-93 inhibits the activity of autophosphorylated CaMKII, consistent with a block of activation but not of catalysis (Tokumitsu et al., 1990; Sumi et al., 1991). Such inhibition can be classified as "ATP non-competitive" or "allosteric" as binding likely occurs outside the active site. Based on an ischemic stroke model, it has been suggested previously that blocking catalytic activity is the more effective approach because autonomous activity is resistant to allosteric inhibition by KN-93 (Vest et al., 2010). The observed differing efficacies, however, may have been due to differences in inhibitor concentrations at the site of action.

KN-93 (and KN-62) likely blocks the ability of $\mathrm{Ca}^{2+} / \mathrm{CaM}$ to wrap around the CaM-binding segment and free it from the catalytic domain. The displacement of the autoinhibitory regulatory segment can be monitored by appropriate FRET pairs and indeed $\mathrm{KN}-93$ blocks the change in FRET signal induced by $\mathrm{Ca}^{2+} / \mathrm{CaM}$ and the change promoted by either autophosphorylation, oxidation, or GlcNAcylation (Erickson et al., 2011, 2013). KN-93 blocks $\mathrm{Ca}^{2+} / \mathrm{CaM}$ from displacing and "presenting" Thr287 to an active neighboring subunit for phosphorylation (Rich and Schulman, 1998). KN-93 similarly blocks presentation of Ser280 for GlcNAcylation (Erickson et al., 2013). Once activated and autophosphorylated, however, KN-93 does not inhibit the kinase, nor is it likely to inhibit kinase made autonomously active by oxidation or GlcNAcylation.

The initial characterization of KN-93 and KN-62 showed them to be selective for CaMKII relative to PKA, PKC and MLCK (Tokumitsu et al., 1990; Sumi et al., 1991), but they were later shown to inhibit CaMKI and CaMKIV equally well (Mochizuki et al., 1993; Enslen et al., 1994). KN-93 is not very potent, inhibiting CaMKII with an IC50 1-4 $\mu \mathrm{M}$ depending on level of CaM and other assay conditions (Sumi et al., 1991; Anderson et al., 1998; Rezazadeh et al., 2006). A recent screen against 234 protein kinases shows that KN-93 is indeed very selective, but its targets now include Fyn, Haspin, Hck, Lck, MLCK, Tec, and TrkA (Gao et al., 2013).

Tool inhibitors are rarely optimized for potency or off-target effects and indeed $\mathrm{KN}-62$ and $\mathrm{KN}-93$, while inhibiting only a few protein kinases, do inhibit many of the ion channels that have been tested. KN-62 and KN-93 block modulation of the L-type $\mathrm{Ca}^{2+}$ channel by CaMKII but also have direct effects on the channel (Li et al., 1992; Anderson et al., 1998) so it is important to use their kinase-inactive controls (KN-04 and $\mathrm{KN}-92)$. KN-62 and KN-93 block macroscopic voltage-dependent $\mathrm{K}^{+}$current $\left(K_{v}\right)$ in smooth muscle cells at concentrations $(0.3-3 \mu \mathrm{M})$ used to inhibit CaMKII (Ledoux et al., 1999). KN-92 similarly blocks the channel and is therefore useful in excluding $\mathrm{K}^{+}$channel effects. A detailed analysis demonstrated that $\mathrm{KN}-93$, but not $\mathrm{KN}-92$, blocked members of the Kv1, Kv2, Kv3, Kv4, and Kv7 (hERG) voltage-gated potassium 


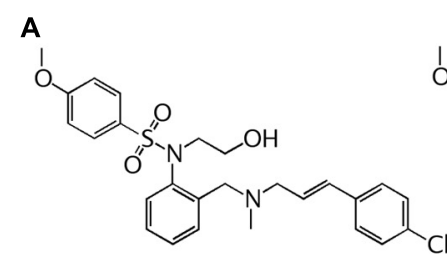

$\mathrm{KN}-93$<smiles>Cc1ccc(S(=O)(=O)Nc2ccccc2CN(C)C/C=C/c2ccc(Cl)cc2)cc1</smiles>

KN-92<smiles>CN(C/C=C/c1ccc(F)cc1)Cc1ccccc1N(CCN)S(=O)(=O)c1ccc(Cl)cc1</smiles>

HMN-709<smiles></smiles><smiles>O=[W]Nc1ccc(CC(CN2CCN(c3ccccc3)CC2)NS(=O)(=O)c2cccc3cnccc23)cc1</smiles>

B

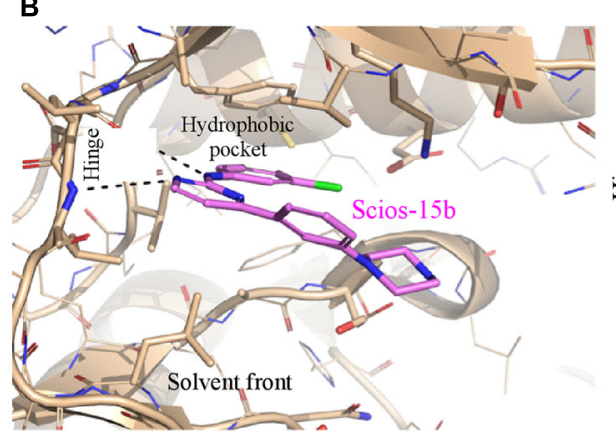<smiles>O=C(N=C1C=NC=NC1Nc1cccc(Cl)c1)c1cccc(N2CCNCC2)c1</smiles>

Solvent front

Scios- $15 b$<smiles>COc1cc(Nc2c(C#N)cnc3cc(OCCCN4CCN(C)CC4)c(OC)cc23)c(Cl)cc1Cl</smiles>

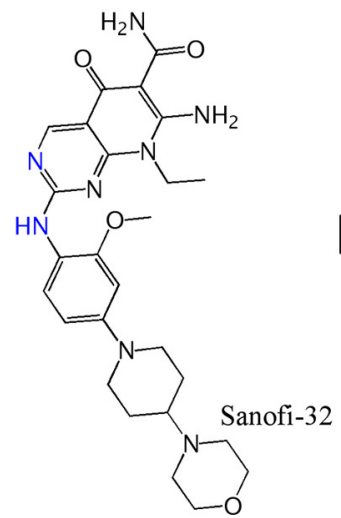<smiles>Cc1c(Cl)cccc1S(=O)(=O)Nc1nc(NCCc2ccccc2)nc2c1CN(Cc1ccccc1)CC2</smiles>

Dainippon A: 8p<smiles>O=C(c1ccc(Oc2ccccc2)cc1)c1cc2c(Br)c(O)c(Br)cc2[nH]1</smiles>

Dainippon B: 25<smiles>C[C@@H](c1ccc(-c2ccccc2)c(F)c1)c1cc(/N=C(\N)N2CCOCC2)on1</smiles>

Rimacalib; SMP-114
FIGURE 2 | Chemical structures of CaMKII inhibitors. (A) The ATP non-competitive inhibitors and controls are: KN-93 (Sumi etal., 1991); KN-92 (Tombes etal., 1995); KN-62 and KN-04 (Ishikawa etal., 1990) HMN-709 (Yokokura etal., 1996). (B) Computational docking of Compound 15b (Mavunkel etal., 2008) illustrates interaction of an ATP competitive inhibitor viewed from the solvent front and shown docked at the kinase "hinge" and interaction at the hydrophobic pocket. The structure of Compound $15 \mathrm{~b}$ is shown, with the same orientation, with residues that interact at the hinge in blue based on either a crystal structures (Bosutinib) or based on modeling when a reasonable docked structure could be obtained. The compounds above are: Scios-15b (Mavunkel etal., 2008); Bosutinib (Chao etal., 2011); Sanofi-32 (Beauverger etal., 2012): Dainippon A: 8p (Asano etal., 2010): Dainippon B: 25 (Komiya etal., 2012); Rimacalib/SMP-114 Mestra etal., 2010). 
channel families at concentrations that also block CaMKII (Rezazadeh et al., 2006). To be broadly useful as a control, it would be ideal if KN-93 and KN-92 had the same pharmacology other than for CaMKII, but this is unfortunately not the case. For example, $\mathrm{KN}-92$ is not as potent in direct inhibition of L-type $\mathrm{Ca}^{2+}$ channels as is KN-93 (Anderson et al., 1998) or as potent in direct inhibition of $\mathrm{IP}_{3}$-induced $\mathrm{Ca}^{2+}$ release via $\mathrm{IP}_{3} \mathrm{R}-1$ (Smyth et al., 2002) and thus not every effect blocked by KN-93 and not by KN-92 can be ascribed to CaMKII. Despite these caveats, these inhibitors have been extremely useful as initial evidence for CaMKII action, as illustrated by several examples in Table $\mathbf{1}$.

It is a bit surprising, given the channel blocking effects of $\mathrm{KN}$ 93, that it has not been as problematic to use it for in situ inhibition of CaMKII, when compared to peptide inhibitors below. The interplay between its effect on $\mathrm{K}^{+}$channels and L-type $\mathrm{Ca}^{2+}$ channels and inhibition of CaMKII are not well understood and complicate arrhythmia studies. Clearly, modification of $\mathrm{K}$ currents, such as in genetic mutations, can lead to arrhythmia, whereas ablation or peptide inhibition of CaMKII are anti-arrhythmic. KN-93 may therefore be anti-arrhythmic despite its $\mathrm{K}^{+}$channel blockade because concurrent inhibition of CaMKII serves as an arrhythmia shield that blocks the pro-arrhythmic consequence of the $\mathrm{K}^{+}$channel inhibition. Alternatively, a significant component of the anti-arrhythmic effect of $\mathrm{KN}-93$ could be to reduce CaMKII activation by inhibiting the L-type $\mathrm{Ca}^{2+}$ channel and lowering free $\mathrm{Ca}^{2+}$ levels. Ultimately, inhibition of CaMKII with small molecule allosteric or ATP competitive inhibitors can be achieved without a significant $\mathrm{K}^{+}$channel component, something that is harder to achieve with channel blockers used as anti-arrhythmic agents.

\section{SUBSTRATE-BASED INHIBITORS: AUTOCAMTIDE-3 INHIBITOR (AC3-I)/AUTOCAMTIDE-2 INHIBITOR PROTEINS (AIP)}

Identification of the autoinhibitory regulatory segment of CaMKII $\alpha$ led to development of long inhibitory peptides lacking the CaM binding sequence (residues 273-302) that could be injected into cells, e.g., implicating CaMKII in functions such as long-term potentiation (Payne et al., 1988; Malinow et al., 1989). The N-terminal end of this peptide contains the autophosphorylation site that was the basis for peptides substrates such as autocamtide- 2 and autocamtide-3 (Hanson et al., 1989) and substitution of the phosphorylatable Thr to an Ala generated the

\section{Table 1 | CaMKII inhibitors and related compounds.}

\begin{tabular}{|c|c|c|}
\hline Inhibitor type & Controls/verification & Action of inhibitor \\
\hline \multirow[t]{4}{*}{ KN-93/KN-62 } & KN-92; GFP-AC3-I transgene & KN-93 blocked pacing induced atrial fibrillation in the Ryr $2^{R 1760 /+}$ mouse model (Chelu et al., 2009). \\
\hline & KN-92; AIP; CaMKIII knockout & $\begin{array}{l}\text { KN-93, AIP, and knockout block cardiac arrhythmogenesis and sarcoplasmic reticulum } \mathrm{Ca}^{2+} \text { leak } \\
\text { (Sag et al., 2009). }\end{array}$ \\
\hline & KN-92 & $\begin{array}{l}\text { KN-93 and AIP were used to demonstrate that CaMKII is linked to SAN cell bioenergetics, affecting } \\
\text { both ATP consumption and ATP generation (Yaniv et al., 2013). }\end{array}$ \\
\hline & KN-92; CaMKII $\delta$ knockout & $\begin{array}{l}\text { KN-93 blocks increase in GlcNAcylation-dependent Ca }{ }^{2+} \text { spark frequency and prevents premature } \\
\text { ventricular complexes also seen in diabetes (Erickson et al., 2013). }\end{array}$ \\
\hline \multirow[t]{4}{*}{ AC3-I/AIP } & GFP-AC3-C & $\begin{array}{l}\text { Myocardial GFP-AC3-I transgene blocked maladaptive remodeling following chronic } \beta \text {-adrenergic } \\
\text { stimulation or myocardial infarct with GFP-AC3-I (Zhang etal., 2005). }\end{array}$ \\
\hline & GFP-AC3-C;KN-93/KN-92 & $\begin{array}{l}\text { Myocardial GFP-AC3-I transgene in calcineurin hypertrophy model primarily reduced ventricular } \\
\text { arrhythmias, improved mechanical function, and decreased mortality with minimal effect on the } \\
\text { hypertrophic phenotype (Khoo et al., 2006). }\end{array}$ \\
\hline & GFP-AC3-C & $\begin{array}{l}\text { Angll promoted AF was blocked by GFP-AC3-I and prevented by knockins with oxidation resistant } \\
\text { CaMKII(MM > VV) or RyR2 lacking CaMKII phosphorylation site (RyR2S2814A; Purohit et al., 2013). }\end{array}$ \\
\hline & GFP-AC3C; CaMKIIN & $\begin{array}{l}\text { Myocardial GFP-AC3-I and blocked increase mortality of diabetic mice after myocardial infarction via } \\
\text { reactive oxygen species and confirmed with CaMKIIMM > VV) mice (Luo et al., 2013). }\end{array}$ \\
\hline \multirow[t]{6}{*}{ CaMKIIN } & Myocardial GFP-AC3-I and -AC3-C & $\begin{array}{l}\text { GFP-CaMKIIN (sinoatrial node expressed) blocked isoproterenol-stimulated CaMKII activation and } \\
\text { reduced the fight or flight heart rate response to stress or isoproterenol Wu etal., 2009). }\end{array}$ \\
\hline & GFP; AC3-I & $\begin{array}{l}\text { GFP-CaMKIIN (sinoatrial node expressed) blocked Angll and ROS activation of CaMKII and cell } \\
\text { death contributing to sinus node dysfunction (Swaminathan et al., 2011). }\end{array}$ \\
\hline & AC3-I; shRNA; KN-93 & $\begin{array}{l}\text { HA-CaMKIIN targeted to cytoplasmic membranes acts outside the nucleus to mediate induction of } \\
\text { complement factor B following myocardial infarct (Singh et al., 2009). }\end{array}$ \\
\hline & CaMKII (Thr287Asp) & mtCaMKIIN (with mitochondrial localization sequence) and palmitoyl-CaMKIIN for membrane \\
\hline & & localization support a role of mitochondrial CaMKII in ischemia reperfusion injury, MI and \\
\hline & & $\begin{array}{l}\text { neurohumoral injury due to increased inner membrane mitochondrial } \mathrm{Ca}^{2+} \text { uniporter current } \\
\text { (Joiner etal., 2012). }\end{array}$ \\
\hline
\end{tabular}


peptide inhibitors AIP (Ishida et al., 1995) and AC3-I (Braun and Schulman, 1995). They inhibit CaMKII with $>100$-fold selectivity relative to $\mathrm{PKC}, \mathrm{PKA}$ and CaMKIV, although their selectivity has not been broadly profiled, e.g., green fluorescent protein (GFP)AC3-I was found to inhibit cellular actions of protein kinase D1 (PKD1) as well as those of CaMKII (Backs et al., 2009). As exemplified in Table 1, peptide inhibitors with internalization sequences for cellular studies or the transgenic expression of the peptides in mice have been critical first steps in delineating cardiovascular functions of CaMKII. Transgenic expression of inhibitor/control pairs can also be used to delineate molecular pathways of gene expression (Singh et al., 2009) and phosphorylation initiated by CaMKII activation (Scholten et al., 2013).

Some caution is warranted in the use of peptide (or small molecule) inhibitors that are often optimistically described as "highly specific inhibitors" when experience or data should suggest otherwise. Useful first generation tool inhibitors are typically developed by academic labs with limited resources, so selectivity is based on a handful of kinases available to the lab rather than on the 50-300 kinases that should be tested. As a minimum, the off-target effects of AC3-I should be checked by use of a control peptide (AC3-C; Patel et al., 1999; Wu et al., 2009). Altered selectivity can also occur when peptides are fused to GFP in order to increase expression and metabolic stability, or modified by lipids or internalization sequences for cell permeation. For example, addition of Ant (Antennapedia) to another peptide inhibitor generated a direct $\mathrm{CaM}$ antagonistic sequence (Buard et al., 2010) and myristoylated AIP and AC3-C were shown to have some effects unrelated to CaMKII inhibition (Wu et al., 2009).

\section{CaMKIIN (CaM-KIIN)}

CaMKIIN or CaM-KIIN designates small endogenous proteins that inhibit CaMKII with high affinity that can be applied pharmacologically or genetically. CaMKIIN was discovered by use of a yeast two-hybrid screen whereby the catalytic domain of CaMKII $\beta$ served as bait to clone interacting proteins from a rat neuronal library (Chang etal., 1998, 2001). Two small proteins sharing high homology were identified and termed CaM-KIIN $\beta$ (79 amino acids) and CaM-KIIN $\alpha$ (78 amino acids) to designate them as inhibitors, and often spelled CaMKIIN. The $\alpha$ and $\beta$ in their names are unrelated to the CaMKII isoform, as either of these inhibits all CaMKII isoforms with IC50 of $50 \mathrm{nM}$ (Chang etal., 2001). The protein has not been detected in heart although a related mRNA was detected (Zhang et al., 2001).

Identification of the core inhibitory domain of CaMKIIN led to generation of a 28 amino acid peptide inhibitor termed CaMKIINtide (Chang et al., 1998) that was subsequently shortened and modified to improve potency (Vest et al., 2007; Coultrap and Bayer, 2011; Gomez-Monterrey et al., 2013). CaMKIIN and CaMKIINtide only bind to the activated conformation of CaMKII, suggesting that they dock to the kinase surface exposed and shaped only after displacement of the autoinhibitory domain during activation. They should therefore inhibit CaMKII activated by bound $\mathrm{Ca}^{2+} / \mathrm{CaM}$ or autonomously active due to autophosphorylation, methionine oxidation, or GlcNAcylation. A 21-residue segment of CaMKIINtide was co-crystallized with CaMKII and shown to dock at the $\mathrm{B} / \mathrm{C}$ sites using hydrophobic and basic residues at its $\mathrm{N}$-terminal region to support potency and specificity and to extend to the A site where it precludes substrate from binding in a manner similar to protein kinase inhibitor (PKI) binding to PKA (Chao et al., 2010; Figure 1).

CaMIINtide has been modified to increase potency (Coultrap and Bayer, 2011; Gomez-Monterrey et al., 2013). In one series of optimizations, a shorter sequence of 21 amino acids (CN21a) was found to retain the potency of CaMKIINtide (Vest et al., 2007). A 19 amino acid sequence was then subjected to Ala scanning substitutions to identify critical residues and subsequent modifications produced a more potent and selective CaMKII inhibitor termed CN19o (Coultrap and Bayer, 2011). CN19o inhibited CaMKII $\alpha$ with IC50 $<0.4 \mathrm{nM}$ and improved selectivity for tested kinases, showing minimal or no inhibition at $5 \mu \mathrm{M}$ against CaMKI, CaMKIV, DAPK1, AMPK, PKC, and PKA. A similar study generated a smaller optimized 17 amino acid peptide, $\mathrm{CN} 17 \beta$, with IC50 of $30 \mathrm{nM}$ and little inhibition of CaMKI or CaMKIV (Gomez-Monterrey et al., 2013).

CaMKIIN and CaMKIINtides are excellent experimental tools being adopted by the field but their use can result in additional effects by blocking interaction of CaMKII with some anchoring proteins and substrates that share the B/C docking sites (Figure 1). Translocation and docking to anchoring proteins aids in fidelity of signal transduction that would be disrupted by CaMKIIN and may generate secondary effects because anchoring proteins often cluster several signaling proteins that might be affected (Colbran, 2004; Schulman, 2004; Tsui et al., 2005). Mutations at the B/C sites block both binding of CN21a and CaMKII translocation/docking to the glutamate NR2B receptor (Leonard et al., 1999; Strack et al., 2000; Bayer and Schulman, 2001; Bayer et al., 2006; Vest et al., 2007) suggesting overlapping binding sites. Application of TatCN21 on neurons inhibits the kinase but also reduces the level of kinase at synaptic sites (Sanhueza etal., 2011), decreases clustering in dendrites, and produces aggregates with polyribosomes (TaoCheng et al., 2013). CaMKIINtides also block interaction with densin (Jiao et al., 2011) and Cav2.1 calcium channels (Magupalli et al., 2013) and possibly with $\beta_{\mathrm{IV}}$-spectrin and other proteins (Hund et al., 2010). Finally, the biological function of CaMKIIN is not fully understood and it may directly affect cellular pathways unrelated to CaMKII inhibition or interference with its translocation.

The cardiovascular field has appropriately advanced from the AC3-I/AIP- to CaMKIIN-based inhibitors to delineate in situ and in vivo functions (Table 1). The inhibitor can be directly introduced in a regionally selective manner via locally applied adenoviral constructs, as a transgene targeted to selective tissues, and even directed to distinct intracellular sites with appropriate targeting sequences.

\section{ERA OF SMALL MOLECULAR THERAPEUTICS}

The inhibitory agents and approaches described above have been essential in identifying key roles of CaMKII in health and disease and make a compelling case for targeting CaMKII for several cardiovascular indications, so as one of us asked previously, "where are the drugs?" (Anderson et al., 2006). While it is possible that 
a CaMKIIN-based inhibitor could be developed as a therapeutic, e.g., for local expression at the sinoatrial node (SAN), new small molecule inhibitors will be needed for treating cardiovascular disease, and these will, in turn, provide better tools for advancing CaMKII research. The period covered since the review above has seen a large increase in the number of protein kinases targeted in oncology, with over 100 hundred in clinical development and many in clinical practice (Cohen and Alessi, 2013). The cardiovascular field, largely because of the greater safety requirements but also because of decades-long investments in ion channel blockers, has been slower in turning to this target class. The message emerging from data published by the CaMKII research field has been heard and now there are several programs targeting CaMKII for cardiovascular indications.

One of the early programs was initiated at Scios, expanded following its acquisition by Johnson and Johnson, and discontinued along with more advanced programs for strategic reasons when Scios was closed. The program did provide some potent ATP competitive inhibitors, along with structure - activity relationships that enables an understanding of how to inhibit CaMKII (Lu et al., 2008; Mavunkel etal., 2008). One of the lead compounds, a pyrimidine (Scios 15b) with IC50 of $9 \mathrm{nM}$ in vitro and $320 \mathrm{nM}$ in situ, is shown in Figure 2B. Bosutinib (and sunitinib) were developed as ATP competitive inhibitors of protein tyrosine kinases but have surprising potency at inhibiting CaMKII and a cocrystal of CaMKII with bosutinib has been published (Chao et al., 2011). Dainippon Sumitomo Pharma has had the most advanced CaMKII program and developed Rimacalib (SMP-114) for treatment of rheumatoid arthritis. It passed the Phase I safety trial, but appears not to have shown efficacy in a 24-week Phase II trial (Tagashira and Fukushima, 2008; Westra et al., 2010). The other compounds are all potent $(2-60 \mathrm{nM})$ inhibitors generated during CaMKII inhibition programs at Sanofi (Beauverger et al., 2012) and Dainippon (Asano et al., 2010; Komiya et al., 2012). Allosteros Therapeutics is developing both ATP-competitive and allosteric or ATP non-competitive inhibitors for cardiovascular and other indications and a CaMKII program at Myogen (with Novartis) was part of an acquisition by Gilead with no publications of structures so far. We are aware of several other early stage CaMKII inhibitor programs and anticipate that both tool inhibitors for academic research as well as new chemical entities for treating cardiovascular disease will arise from several of these programs.

The biochemical properties of some the best characterized CaMKII inhibitors are summarized in Table 2.

\section{INHIBITOR DESIGN}

CaMKII is now accepted as a key target in cardiovascular disease and the focus is shifting to creation of selective inhibitors that are safe and effective for therapeutic use. The global market for kinase inhibitors is over $\$ 30 \mathrm{~B}$, mostly targeting protein tyrosine kinases with both biologics and small molecules. Structure-guided drug design and virtual library and fragment screening are likely to benefit from the recent availability of high resolution crystal structures of CaMKII in various conformations. Targeting the ATP-binding site is the most common approach with small molecule inhibitors; however, specificity becomes a challenge because there are over 500 kinases whose active conformation of the site have a similar shape and amino acid composition. Their potency must also be very high in order to compete with millimolar levels of cellular ATP. Successful development of ATP competitive inhibitors for oncology indications has demonstrated that appropriate selectivity is achievable. The first generation of CaMKII therapeutics will likely target the ATP-binding site because of the large body of structural information and medicinal chemistry experience that facilitates the design of relatively selective ATP competitive inhibitors.

The role of CaMKII in cognitive memory and neuronal plasticity that involves its $\alpha$ and $\beta$ isoforms in brain necessitates development of inhibitors do not block these isoforms in brain, certainly when intended for long-term or chronic use. One approach is gene therapy with viral vectors for expression of peptides or proteins, such as SERCA2a or S100A1 to the heart or specific or very localized regions of heart, such as SAN by intracoronary application or endocardial injection by catheter (Pleger et al., 2013). This type of approach for CaMKII inhibitory proteins, coupled with cardiac-selective promoters, would minimize expression outside the heart and would certainly avoid expression in brain. However, widespread adoption will need to await successful and safe demonstration of exemplary cardiac gene therapy

Table 2 | Biochemical properties of best characterized CaMKII inhibitors.

\begin{tabular}{|c|c|c|c|}
\hline Inhibitor & Mechanism of action & $\begin{array}{l}\text { Autonomous }{ }^{a} \text { kinase } \\
\text { inhibition }\end{array}$ & Off-target effects \\
\hline $\mathrm{KN}-93, \mathrm{KN}-62$ & Allosteric, CaM-competitive & No & CaMKI, CaMKIV, ion channels \\
\hline AC3I/AIP & Peptide substrate-competitive & Yes & PKD-1 in cells \\
\hline CaMKIIN & Peptide substrate/regulatory domain-competitive & Yes & None identified \\
\hline $\begin{array}{l}\text { Small molecule } \\
\text { inhibitors (Scios 15b, } \\
\text { SMP-114, Bosutinib) }\end{array}$ & ATP-competitive & Yes & Inhibit other ser/thr and tyr kinases in vivo \\
\hline
\end{tabular}

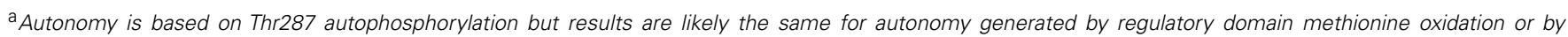
GlcNAcylation. 
such gene therapy on a larger scale. Gene therapy still holds great promise. For CaMKII inhibition, it promises a lower threshold for success in attaining limiting exposure to heart and avoiding effects in brain and other organs, but it still has a much higher threshold in the development and regulatory path than development of small molecule inhibitors.

For small molecule inhibitors inhibition of $\alpha$ - and $\beta$-CaMKII in brain can be minimized by reducing CNS penetration through optimization of their pharmacokinetic properties. There is a large body of literature of physical and structural properties that either promote or limit CNS penetration and typically there are sites on the molecules not involved in target binding that are optimized for solubility, plasma protein binding, and CNS penetration. In addition, while the ATP-binding pockets of the four CaMKII isoforms are similar, it should be possible to further reduce CNS action by perhaps a 10 -fold selectivity for $\delta$ - over $\alpha$ - and $\beta$-CaMKII. The $\beta$ isoform, in particular, has a slight folding down of the phosphatebinding loop as well as a bulkier amino acid side chain not seen in the other three isoforms making it possible to achieve significant discrimination for this isoform.

A strategy designed to circumvent the high redundancy associated with kinases in the active conformation is to target the more diverse inactive conformation (Huse and Kuriyan, 2002). The anti-cancer drug imatinib $\left(\right.$ Gleevec $\left.^{\circledR}\right)$ exhibits a high degree of selectivity for its target Bcr-Abl because, in addition to partially occupying the ATP-binding site, it recognizes a distinctive conformation of the "activation" loop seen only in the inactive state (Schindler et al., 2000; Nagar et al., 2002). It is more difficult to use this strategy for CaMKII because the ATP-binding site is not so different in the active and inactive states. However, because CaMKII is subjected to complex and multilayered mechanisms of regulation, inhibition strategies extending beyond the ATP-binding pocket may be possible.

Allosteric inhibitors, molecules that inhibit enzyme function by binding outside of the active site, show higher selectivity profiles for their targets because such sites are not conserved or even broadly present in the kinome. KN-93 and KN-62 appear to be allosteric inhibitors that may stabilize the interaction between the autoinhibitory regulatory segment and kinase domain and may thereby hinder activation by $\mathrm{Ca}^{2+} / \mathrm{CaM}$ (Figure 1). Although the novelty of their unidentified binding sites makes it more challenging to optimize allosteric inhibitors, they offer the advantage of greater selectivity and binding unaffected by high cellular ATP concentrations.

Selectivity would be most easily achieved at unique sites on the kinase. For example, docking sites $\mathrm{B} / \mathrm{C}$ uncovered in the recent crystal structures may be amenable to medicinal chemistry (Chao et al., 2010; Figure 1). It may be possible to block some CaMKII signaling by blocking its targeting to anchoring proteins via the $\mathrm{B} / \mathrm{C}$ sites as blocking anchoring can decrease phosphorylation even if catalytic activity is not blocked (Tsui et al., 2005). Additionally, it may be possible to achieve target specificity by blocking exposure of the site on substrates or anchoring proteins that interacts with the $\mathrm{B} / \mathrm{C}$ site. In that case only one or a subset of the multiple CaMKII substrates would be affected. In many cases, however, the phosphorylation site on kinase substrates tends to be exposed, making it difficult to block with a small molecule inhibitor.
The most unique region of CaMKII is the linker region between the catalytic and hub domains (Tombes et al., 2003). Linker length affects the equilibrium between compact and extended holoenzyme conformations and the sensitivity of the kinase to the frequency of $\mathrm{Ca}^{2+}$ pulses (Bayer et al., 2002; Chao et al., 2011). Thus, in principle, CaMKII inhibition can be achieved by favoring a more compact holoenzyme and reducing its $\mathrm{Ca}^{2+}$ sensitivity. It is likely that the first generation of CaMKII therapeutics will be ATP competitive inhibitors with others following that exploit more unique sites thus enabling fewer off-target effects and safer use for more chronic and less severe indications.

\section{REFERENCES}

Anderson, M. E., Braun, A. P., Wu, Y., Lu, T., Wu, Y., Schulman, H., et al. (1998). KN93, an inhibitor of multifunctional $\mathrm{Ca}^{2+} /$ calmodulin-dependent protein kinase, decreases early after depolarizations in rabbit heart. J. Pharmacol. Exp. Ther. 287, 996-1006.

Anderson, M. E., Brown, J. H., and Bers, D. M. (2011). CaMKII in myocardial hypertrophy and heart failure. J. Mol. Cell Cardiol. 51, 468-473. doi: 10.1016/j.yjmcc.2011.01.012

Anderson, M. E., Higgins, L. S., and Schulman, H. (2006). Disease mechanisms and emerging therapies: protein kinases and their inhibitors in myocardial disease. Nat. Clin. Pract. Cardiovasc. Med. 3, 437-445. doi: 10.1038/ ncpcardio0585

Asano, S., Komiya, M., Koike, N., Koga, E., Nakatani, S., and Isobe, Y. (2010). 5,6,7,8-Tetrahydropyrido[4,3-d]pyrimidines as novel class of potent and highly selective CaMKII inhibitors. Bioorg. Med. Chem. Lett. 20, 6696-6698. doi: 10.1016/j.bmcl.2010.09.005

Backs, J., Backs, T., Neef, S., Kreusser, M. M., Lehmann, L. H., Patrick, D. M., et al. (2009). The $\delta$ isoform of CaM kinase II is required for pathological cardiac hypertrophy and remodeling after pressure overload. Proc. Natl. Acad. Sci. U.S.A. 106, 2342-2347. doi: 10.1073/pnas.0813013106

Bayer, K. U., De Koninck, P., and Schulman, H. (2002). Alternative splicing modulates the frequency-dependent response of CaMKII to $\mathrm{Ca}^{2+}$ oscillations. EMBO J. 21, 3590-3597. doi: 10.1093/emboj/cdf360

Bayer, K. U., Lebel, E., Mcdonald, G. L., O'Leary, H., Schulman, H., and De Koninck, P. (2006). Transition from reversible to persistent binding of CaMKII to postsynaptic sites and NR2B. J. Neurosci. 26, 1164-1174. doi: 10.1523/JNEUROSCI.3116-05.2006

Bayer, K. U., and Schulman, H. (2001). Regulation of signal transduction by protein targeting: the case for CaMKII. Biochem. Biophys. Res. Commun. 289, 917-923. doi: 10.1006/bbrc.2001.6063

Beauverger, P., Gegis, G., Biscarrat, S., Duclos, O., and McCort, G. (2012). 5-Oxo5,8-dihydropyrido[2,3-d]pyrimidine derivatives as CaMKII kinase inhibitors for treating cardiovascular diseases. US Patent, 0277 220, 2012-11-01.

Braun, A. P., and Schulman, H. (1995). A non-selective cation current activated via the multifunctional $\mathrm{Ca}^{2+}$-calmodulin-dependent protein kinase in human epithelial cells. J. Physiol. 488(Pt 1), 37-55.

Buard, I., Coultrap, S. J., Freund, R. K., Lee, Y. S., Dell'acqua, M. L., Silva, A. J., et al. (2010). CaMKII "autonomy" is required for initiating but not for maintaining neuronal long-term information storage. J. Neurosci. 30, 8214-8220. doi: 10.1523/JNEUROSCI.1469-10.2010

Chang, B. H., Mukherji, S., and Soderling, T. R. (1998). Characterization of a calmodulin kinase II inhibitor protein in brain. Proc. Natl. Acad. Sci. U.S.A. 95, 10890-10895. doi: 10.1073/pnas.95.18.10890

Chang, B. H., Mukherji, S., and Soderling, T. R. (2001). Calcium/calmodulindependent protein kinase II inhibitor protein: localization of isoforms in rat brain. Neuroscience 102, 767-777. doi: 10.1016/S0306-4522(00)00520-0

Chao, L. H., Pellicena, P., Deindl, S., Barclay, L. A., Schulman, H., and Kuriyan, J. (2010). Intersubunit capture of regulatory segments is a component of cooperative CaMKII activation. Nat. Struct. Mol. Biol. 17, 264-272. doi: $10.1038 / \mathrm{nsmb} .1751$

Chao, L. H., Stratton, M. M., Lee, I. H., Rosenberg, O. S., Levitz, J., Mandell, D. J., et al. (2011). A mechanism for tunable autoinhibition in the structure of a human $\mathrm{Ca}^{2+} /$ calmodulin-dependent kinase II holoenzyme. Cell 146, 732-745. doi: 10.1016/j.cell.2011.07.038 
Chelu, M. G., Sarma, S., Sood, S., Wang, S., Van Oort, R. J., Skapura, D. G., et al. (2009). Calmodulin kinase II-mediated sarcoplasmic reticulum $\mathrm{Ca}^{2+}$ leak promotes atrial fibrillation in mice. J. Clin. Invest. 119, 1940-1951. doi: 10.1172/JCI37059

Cohen, P., and Alessi, D. R. (2013). Kinase drug discovery-what's next in the field? ACS Chem. Biol. 8, 96-104. doi: 10.1021/cb300610s

Colbran, R. J., Smith, M. K., Schworer, C. M., Fong, Y. L., and Soderling, T. R. (1989). Regulatory domain of calcium/calmodulin-dependent protein kinase II Mechanism of inhibition and regulation by phosphorylation. J. Biol. Chem. 264, 4800-4804.

Colbran R. J. (2004). Targeting of calcium/calmodulin-dependent protein kinase II. Biochem. J. 378, 1-16. doi: 10.1042/BJ20031547

Coultrap, S. J., and Bayer, K. U. (2011). Improving a natural CaMKII inhibitor by random and rational design. PLOS ONE 6:e25245. doi: 10.1371/journal.pone.0025245

Enslen, H., Sun, P., Brickey, D., Soderling, S. H., Klamo, E., and Soderling, T. R. (1994). Characterization of $\mathrm{Ca}^{2+} /$ calmodulin-dependent protein kinase IV. Role in transcriptional regulation. J. Biol. Chem. 269, 15520-15527.

Erickson, J. R., Joiner, M. L., Guan, X., Kutschke, W., Yang, J., Oddis, C. V., et al (2008). A dynamic pathway for calcium-independent activation of CaMKII by methionine oxidation. Cell 133, 462-474. doi: 10.1016/j.cell.2008.02.048

Erickson, J. R., Patel, R., Ferguson, A., Bossuyt, J., and Bers, D. M. (2011). Fluorescence resonance energy transfer-based sensor Camui provides new insight into mechanisms of calcium/calmodulin-dependent protein kinase II activation in intact cardiomyocytes. Circ. Res. 109, 729-738. doi: 10.1161/CIRCRESAHA.111.247148

Erickson, J. R., Pereira, L., Wang, L., Han, G., Ferguson, A., Dao, K., et al. (2013). Diabetic hyperglycaemia activates CaMKII and arrhythmias by O-linked glycosylation. Nature 502, 372-376. doi: 10.1038/nature12537

Gao, Y., Davies, S. P., Augustin, M., Woodward, A., Patel, U. A., Kovelman, R., et al. (2013). A broad activity screen in support of a chemogenomic map for kinase signalling research and drug discovery. Biochem. J. 451, 313-328. doi: 10.1042/BJ20121418

Gomez-Monterrey, I., Sala, M., Rusciano, M. R., Monaco, S., Maione, A. S., Iaccarino, G., et al. (2013). Characterization of a selective CaMKII peptide inhibitor. Eur. J. Med. Chem. 62, 425-434. doi: 10.1016/j.ejmech.2012. 12.053

Gutierrez, D. A., Fernandez-Tenorio, M., Ogrodnik, J., and Niggli, E. (2013). NOdependent CaMKII activation during $\beta$-adrenergic stimulation of cardiac muscle. Cardiovasc. Res. 100, 392-401. doi: 10.1093/cvr/cvt201

Hanson, P. I., Kapiloff, M. S., Lou, L. L., Rosenfeld, M. G., and Schulman, H. (1989). Expression of a multifunctional $\mathrm{Ca}^{2+} /$ calmodulin-dependent protein kinase and mutational analysis of its autoregulation. Neuron 3, 59-70. doi: 10.1016/08966273(89)90115-3

Hanson, P. I., Meyer, T., Stryer, L., and Schulman, H. (1994). Dual role of calmodulin in autophosphorylation of multifunctional CaM kinase may underlie decoding of calcium signals. Neuron 12, 943-956. doi: 10.1016/0896-6273(94)90306-9

Hudmon, A., and Schulman, H. (2002). Neuronal $\mathrm{Ca}^{2+} /$ calmodulindependent protein kinase II: the role of structure and autoregulation in cellular function. Annu. Rev. Biochem. 71, 473-510. doi: 10.1146/annurev.biochem.71.110601.135410

Hund, T. J., Koval, O. M., Li, J., Wright, P. J., Qian, L., Snyder, J. S., et al. (2010). A $\beta(I V)$-spectrin/CaMKII signaling complex is essential for membrane excitability in mice. J. Clin. Invest. 120, 3508-3519. doi: 10.1172/JCI43621

Huse, M., and Kuriyan, J. (2002). The conformational plasticity of protein kinases. Cell 109, 275-282. doi: 10.1016/S0092-8674(02)00741-9

Ishida, A., Kameshita, I., Okuno, S., Kitani, T., and Fujisawa, H. (1995). A novel highly specific and potent inhibitor of calmodulin-dependent protein kinase II. Biochem. Biophys. Res. Commun. 212, 806-812. doi: 10.1006/bbrc. 1995.2040

Ishikawa, N., Hashiba, Y., and Hidaka, H. (1990). Effect of a new $\mathrm{Ca}^{2+}$-calmodulindependent protein kinase II inhibitor on GABA release in cerebrospinal fluid of the rat. J. Pharmacol. Exp. Ther. 254, 598-602.

Jiao, Y., Jalan-Sakrikar, N., Robison, A. J., Baucum, A. J. II, Bass, M. A., and Colbran, R. J. (2011). Characterization of a central $\mathrm{Ca}^{2+} /$ calmodulin-dependent protein kinase IIalpha/beta binding domain in densin that selectively modulates glutamate receptor subunit phosphorylation. J. Biol. Chem. 286, 24806-24818. doi: 10.1074/jbc.M110.216010
Joiner, M. L., Koval, O. M., Li, J., He, B. J., Allamargot, C., Gao, Z., et al. (2012). CaMKII determines mitochondrial stress responses in heart. Nature 491, 269273. doi: 10.1038/nature11444

Khoo, M. S., Li, J., Singh, M. V., Yang, Y., Kannankeril, P., Wu, Y., et al. (2006). Death, cardiac dysfunction, and arrhythmias are increased by calmodulin kinase II in calcineurin cardiomyopathy. Circulation 114, 1352-1359. doi: 10.1161/CIRCULATIONAHA.106.644583

Kolodziej, S. J., Hudmon, A., Waxham, M. N., and Stoops, J. K. (2000). Threedimensional reconstructions of calcium/calmodulin-dependent (CaM) kinase II $\alpha$ and truncated CaM kinase IIalpha reveal a unique organization for its structural core and functional domains. J. Biol. Chem. 275, 14354-14359. doi: 10.1074/jbc.275.19.14354

Komiya, M., Asano, S., Koike, N., Koga, E., Igarashi, J., Nakatani, S., et al. (2012). Synthesis and structure based optimization of 2-(4-phenoxybenzoyl)-5hydroxyindole as a novel CaMKII inhibitor. Bioorg. Med. Chem. 20, 6840-6847. doi: 10.1016/j.bmc.2012.09.048

Ledoux, J., Chartier, D., and Leblanc, N. (1999). Inhibitors of calmodulin-dependent protein kinase are nonspecific blockers of voltage-dependent $\mathrm{K}^{+}$channels in vascular myocytes. J. Pharmacol. Exp. Ther. 290, 1165-74.

Leonard, A. S., Lim, I. A., Hemsworth, D. E., Horne, M. C., and Hell, J. W. (1999). Calcium/calmodulin-dependent protein kinase II is associated with the N-methyl-D-aspartate receptor. Proc. Natl. Acad. Sci. U.S.A. 96, 3239-3244. doi: 10.1073/pnas.96.6.3239

Li, G., Hidaka, H., and Wollheim, C. B. (1992). Inhibition of voltage-gated $\mathrm{Ca}^{2+}$ channels and insulin secretion in HIT cells by the $\mathrm{Ca}^{2+} /$ calmodulin-dependent protein kinase II inhibitor KN-62: comparison with antagonists of calmodulin and L-type $\mathrm{Ca}^{2+}$ channels. Mol. Pharmacol. 42, 489-488.

Lu, Q., Chen, Z., Perumattam, J., Wang, D. X., Liang, W., Xu, Y. J., et al.

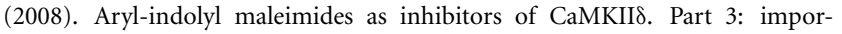
tance of the indole orientation. Bioorg. Med. Chem. Lett. 18, 2399-2403. doi: 10.1016/j.bmcl.2008.02.057

Luo, M., Guan, X., Luczak, E. D., Lang, D., Kutschke, W., Gao, Z., et al. (2013). Diabetes increases mortality after myocardial infarction by oxidizing CaMKII. J. Clin. Invest. 123, 1262-1274. doi: 10.1172/JCI65268

Magupalli, V. G., Mochida, S., Yan, J., Jiang, X., Westenbroek, R. E., Nairn, A. C., et al. (2013). $\mathrm{Ca}^{2+}$-independent activation of $\mathrm{Ca}^{2+} /$ calmodulin-dependent protein kinase II bound to the C-terminal domain of CaV2.1 calcium channels. J. Biol. Chem. 288, 4637-4648. doi: 10.1074/jbc.M112.369058

Malinow, R., Schulman, H., and Tsien, R. W. (1989). Inhibition of postsynaptic PKC or CaMKII blocks induction but not expression of LTP. Science 245, 862-866. doi: 10.1126/science. 2549638

Mavunkel, B., Xu, Y. J., Goyal, B., Lim, D., Lu, Q., Chen, Z., et al. (2008). Pyrimidinebased inhibitors of CaMKIId. Bioorg. Med. Chem. Lett. 18, 2404-2408. doi: 10.1016/j.bmcl.2008.02.056

Mochizuki, H., Ito, T., and Hidaka, H. (1993). Purification and characterization of $\mathrm{Ca}^{2+} /$ calmodulin-dependent protein kinase V from rat cerebrum. J. Biol. Chem. 268, 9143-9147.

Morris, E. P., and Torok, K. (2001). Oligomeric structure of alpha-calmodulindependent protein kinase II. J. Mol. Biol. 308, 1-8. doi: 10.1006/jmbi.2001.4584

Nagar, B., Bornmann, W. G., Pellicena, P., Schindler, T., Veach, D. R., Miller, W. T., et al. (2002). Crystal structures of the kinase domain of c-Abl in complex with the small molecule inhibitors PD173955 and imatinib (STI-571). Cancer Res. 62, 4236-4243.

Patel, R., Holt, M., Philipova, R., Moss, S., Schulman, H., Hidaka, H., et al. (1999). Calcium/calmodulin-dependent phosphorylation and activation of human Cdc25-C at the G2/M phase transition in HeLa cells. J. Biol. Chem. 274, 7958-7968. doi: 10.1074/jbc.274.12.7958

Payne, M. E., Fong, Y. L., Ono, T., Colbran, R. J., Kemp, B. E., Soderling, T. R., et al. (1988). Calcium/calmodulin-dependent protein kinase II. Characterization of distinct calmodulin binding and inhibitory domains. J. Biol. Chem. 263, 71907195.

Pleger, S. T., Brinks, H., Ritterhoff, J., Raake, P., Koch, W. J., Katus, H. A., etal. (2013). Heart failure gene therapy: the path to clinical practice. Circ. Res. 113, 792-809. doi: 10.1161/CIRCRESAHA.113. 300269

Purohit, A., Rokita, A. G., Guan, X., Chen, B., Koval, O. M., Voigt, N., et al. (2013). Oxidized $\mathrm{Ca}^{2+} /$ calmodulin-dependent protein kinase II triggers atrial fibrillation. Circulation 128, 1748-1757. doi: 10.1161/CIRCULATIONAHA.113.003313 
Rellos, P., Pike, A. C. W., Niesen, F. H., Salah, E., Lee, W. H., Von Delft, F., et al. (2010). Structure of the CaMKII $/$ /calmodulin complex reveals the molecular mechanism of CaMKII kinase activation. PLoS Biol. 8:e1000426. doi: 10.1371/journal.pbio.1000426

Rezazadeh, S., Claydon, T. W., and Fedida, D. (2006). KN-93 (2-[N-(2hydroxyethyl)]-N-(4-methoxybenzenesulfonyl) ] amino-N-(4-chlorocinn amyl)$\mathrm{N}$-methylbenzylamine), a calcium/calmodulin-dependent protein kinase II inhibitor, is a direct extracellular blocker of voltage-gated potassium channels. J. Pharmacol. Exp. Ther. 317, 292-299. doi: 10.1124/jpet.105.097618

Rich, R. C., and Schulman, H. (1998). Substrate-directed function of calmodulin in autophosphorylation of $\mathrm{Ca}^{2+} /$ calmodulin-dependent protein kinase II. J. Biol. Chem. 273, 28424-28429. doi: 10.1074/jbc.273.43.28424

Rosenberg, O. S., Deindl, S., Sung, R. J., Nairn, A. C., and Kuriyan, J. (2005) Structure of the autoinhibited kinase domain of CaMKII and SAXS analysis of the holoenzyme. Cell 123, 849-860. doi: 10.1016/j.cell.2005.10.029

Sag, C. M., Wadsack, D. P., Khabbazzadeh, S., Abesser, M., Grefe, C., Neumann, K., et al. (2009). Calcium/calmodulin-dependent protein kinase II contributes to cardiac arrhythmogenesis in heart failure. Circ. Heart Fail. 2, 664-675. doi: 10.1161/CIRCHEARTFAILURE.109.865279

Sanders, P. N., Koval, O. M., Jaffer, O. A., Prasad, A. M., Businga, T. R., Scott, J. A., et al. (2013). CaMKII is essential for the proasthmatic effects of oxidation. Sci. Transl. Med. 5, 195ra197. doi: 10.1126/scitranslmed.3006135

Sanhueza, M., Fernandez-Villalobos, G., Stein, I. S., Kasumova, G., Zhang, P., Bayer, K. U., et al. (2011). Role of the CaMKII/NMDA receptor complex in the maintenance of synaptic strength. J. Neurosci. 31, 9170-9178. doi: 10.1523/JNEUROSCI.1250-11.2011

Schindler, T., Bornmann, W., Pellicena, P., Miller, W. T., Clarkson, B., and Kuriyan, J. (2000). Structural mechanism for STI-571 inhibition of abelson tyrosine kinase. Science 289, 1938-1942. doi: 10.1126/science.289.5486.1938

Scholten, A., Preisinger, C., Corradini, E., Bourgonje, V. J., Hennrich, M. L., Van Veen, T. A., et al. (2013). Phosphoproteomics study based on in vivo inhibition reveals sites of calmodulin-dependent protein kinase II regulation in the heart. J. Am. Heart Assoc. 2:e00318. doi: 10.1161/JAHA.113.000318

Schulman, H. (2004). Activity-dependent regulation of calcium/calmodulindependent protein kinase II localization. J. Neurosci. 24, 8399-8403. doi 10.1523/JNEUROSCI.3606-04.2004

Singh, M. V., Kapoun, A., Higgins, L., Kutschke, W., Thurman, J. M., Zhang, R., et al (2009). $\mathrm{Ca}^{2+} /$ calmodulin-dependent kinase II triggers cell membrane injury by inducing complement factor B gene expression in the mouse heart. J. Clin. Invest. 119, 986-996. doi: 10.1172/JCI35814

Smyth, J. T., Abbott, A. L., Lee, B., Sienaert, I., Kasri, N. N., De Smedt, H., et al. (2002). Inhibition of the inositol trisphosphate receptor of mouse eggs and A7r5 cells by $\mathrm{KN}-93$ via a mechanism unrelated to $\mathrm{Ca}^{2+} /$ calmodulindependent protein kinase II antagonism. J. Biol. Chem. 277, 35061-35070. doi: 10.1074/jbc.M202928200

Strack, S., Mcneill, R. B., and Colbran, R. J. (2000). Mechanism and regulation of calcium/calmodulin-dependent protein kinase II targeting to the NR2B subunit of the N-methyl-D-aspartate receptor. J. Biol. Chem. 275, 23798-23806. doi: 10.1074/jbc.M001471200

Sumi, M., Kiuchi, K., Ishikawa, T., Ishii, A., Hagiwara, M., Nagatsu, T., et al. (1991). The newly synthesized selective $\mathrm{Ca}^{2+} /$ calmodulin dependent protein kinase II inhibitor KN-93 reduces dopamine contents in $\mathrm{PC} 12 \mathrm{~h}$ cells. Biochem. Biophys. Res. Commun. 181, 968-975. doi: 10.1016/0006-291X(91)92031-E

Swaminathan, P. D., Purohit, A., Soni, S., Voigt, N., Singh, M. V., Glukhov, A. V., et al. (2011). Oxidized CaMKII causes cardiac sinus node dysfunction in mice. J. Clin. Invest. 121, 3277-3288. doi: 10.1172/JCI57833

Swulius, M. T., and Waxham, M. N. (2008). $\mathrm{Ca}^{2+} /$ calmodulin-dependent protein kinases. Cell Mol. Life Sci. 65, 2637-2657. doi: 10.1007/s00018-008-8086-2

Tagashira, S., and Fukushima, A. (2008). Combination drug for treating autoimmune disease. US Patent, 0255 121, 2008-10-16.

Tao-Cheng, J. H., Yang, Y., Bayer, K. U., Reese, T. S., and Dosemeci, A. (2013). Effects of CaMKII inhibitor tatCN21 on activity-dependent redistribution of CaMKII in hippocampal neurons. Neuroscience 244, 188-196. doi: 10.1016/j.neuroscience.2013.03.063
Tokumitsu, H., Chijiwa, T., Hagiwara, M., Mizutani, A., Terasawa, M., and Hidaka, H. (1990). KN-62, 1-[N,O-bis(5-isoquinolinesulfonyl)-N-methyl-L-tyrosyl]-4phenylpiperazine, a specific inhibitor of $\mathrm{Ca}^{2+} /$ calmodulin-dependent protein kinase II. J. Biol. Chem. 265, 4315-4320.

Tombes, R. M., Faison, M. O., and Turbeville, J. M. (2003). Organization and evolution of multifunctional $\mathrm{Ca}^{2+} / \mathrm{CaM}$-dependent protein kinase genes. Gene 322, 17-31. doi: 10.1016/j.gene.2003.08.023

Tombes, R. M., Grant, S., Westin, E. H., and Krystal, G. (1995). G1 cell cycle arrest and apoptosis are induced in NIH 3T3 cells by KN-93, an inhibitor of CaMK-II (the multifunctional $\mathrm{Ca}^{2+} / \mathrm{CaM}$ kinase). Cell Growth Differ. 6, 1063-1070.

Tsui, J., Inagaki, M., and Schulman, H. (2005). Calcium/calmodulin-dependent protein kinase II (CaMKII) localization acts in concert with substrate targeting to create spatial restriction for phosphorylation. J. Biol. Chem. 280, 9210-9216. doi: 10.1074/jbc.M407653200

Vest, R. S., Davies, K. D., O’leary, H., Port, J. D., and Bayer, K. U. (2007). Dual mechanism of a natural CaMKII inhibitor. Mol. Biol. Cell 18, 5024-5033. doi: 10.1091/mbc.E07-02-0185

Vest, R. S., O’leary, H., Coultrap, S. J., Kindy, M. S., and Bayer, K. U. (2010). Effective post-insult neuroprotection by a novel CaMKII inhibitor. J. Biol. Chem. 285, 20675-20682. doi: 10.1074/jbc.M109.088617

Westra, J., Brouwer, E., Van Roosmalen, I. A. M., Doornbos-Van Der Meer, B., Van Leeuwen, M. A., Posthumus, M. D., et al. (2010). Expression and regulation of HIF-1alpha in macrophages under inflammatory conditions; significant reduction of VEGF by CaMKII inhibitor. BMC Musculoskelet. Disord. 11:61. doi: 10.1186/1471-2474-11-61.

Woodgett, J. R., Davison, M. T., and Cohen, P. (1983). The calmodulindependent glycogen synthase kinase from rabbit skeletal muscle. Purification, subunit structure and substrate specificity. Eur. J. Biochem. 136, 481-487. doi: 10.1111/j.1432-1033.1983.tb07766.x

Wu, Y., Gao, Z., Chen, B., Koval, O. M., Singh, M. V., Guan, X., et al. (2009). Calmodulin kinase II is required for fight or flight sinoatrial node physiology. Proc. Natl. Acad. Sci. U.S.A. 106, 5972-5977. doi: 10.1073/pnas. 0806422106

Yaniv, Y., Spurgeon, H. A., Ziman, B. D., and Lakatta, E. G. (2013). Ca ${ }^{2+} /$ calmodulindependent protein kinase II (CaMKII) activity and sinoatrial nodal pacemaker cell energetics. PLoS ONE 8:e57079. doi: 10.1371/journal.pone.0057079

Yokokura, H., Okada, Y., Terada, O., and Hidaka, H. (1996). HMN-709, a chlorobenzenesulfonamide derivative, is a new membrane-permeable calmodulin antagonist. Jpn. J. Pharmacol. 72, 127-135. doi: 10.1254/jjp.72.127

Zhang, J., Li, N., Yu, J., Zhang, W., and Cao, X. (2001). Molecular cloning and characterization of a novel calcium/calmodulin-dependent protein kinase II inhibitor from human dendritic cells. Biochem. Biophys. Res. Commun. 285, 229-234. doi: 10.1006/bbrc.2001.5175

Zhang, R., Khoo, M. S., Wu, Y., Yang, Y., Grueter, C. E., Ni, G., et al. (2005). Calmodulin kinase II inhibition protects against structural heart disease. Nat. Med. 11, 409-417. doi: 10.1038/nm1215

Conflict of Interest Statement: The authors declare that the research was conducted in the absence of any commercial or financial relationships that could be construed as a potential conflict of interest.

Received: 21 December 2013; accepted: 03 February 2014; published online: 20 February 2014.

Citation: Pellicena P and Schulman H (2014) CaMKII inhibitors: from research tools to therapeutic agents. Front. Pharmacol. 5:21. doi: 10.3389/fphar.2014.00021

This article was submitted to Pharmacology of Ion Channels and Channelopathies, a section of the journal Frontiers in Pharmacology.

Copyright (C) 2014 Pellicena and Schulman. This is an open-access article distributed under the terms of the Creative Commons Attribution License (CC BY). The use, distribution or reproduction in other forums is permitted, provided the original author(s) or licensor are credited and that the original publication in this journal is cited, in accordance with accepted academic practice. No use, distribution or reproduction is permitted which does not comply with these terms. 